\title{
Reflecting on the Design Process of the Affective Diary
}

\author{
Anna Ståhl \\ Swedish Institute of Computer Science \\ Box 1263 \\ 16429 Kista, Sweden \\ +46706530720 \\ annas@sics.se
}

\author{
Kristina Höök \\ Mobil Life Center at Stockholm University \\ Forum 100 \\ 16440 Kista, Sweden \\ +4686331514 \\ kia@sics.se
}

\begin{abstract}
Affective Diary is a digital diary that makes use of bio-sensors to add some reminiscence of bodily experiences. The design process behind Affective Diary was 'sensitive' to three design qualities extracted from a previous project; providing cues of emotional expressivity building on familiarity, making the design open for personal expressivity and be aware of contradictions between modalities. Through the design process of Affective Diary, with frequent user involvements during the process, these design qualities became further tested, developed and refined. By providing a fairly detailed and reflected description of the design process behind Affective Diary, we aim to provide other designers with inspiration on several levels: both in terms of methods used, but also in why these three design qualities are important and how to realize them. Our aim is also to provide designers with knowledge in the form that makes sense to designers: the practical link between design qualities and final results.
\end{abstract}

\section{Categories and Subject Descriptors}

H.5.2 Classification, Information Interface and Presentation: User Interfaces: Graphical user interfaces

\section{General Terms}

Design

\section{Keywords}

Interaction design, design process, affective interaction

\section{INTRODUCTION}

In here we aim to describe a reflected account of the design process of the Affective Diary system [10]. We want to show an alternative way of proving and describing design knowledge which is different from the traditional HCI (Human-Computer Interaction) way [4]. In HCI, how the actual design was done, the steps from guidelines or sought qualities to the actual designed system, is often black-boxed. The validation of a research result is mainly done through user studies. The actual qualities of the design as such and how those were constructed, is typically not accounted for. We therefore want to show how certain details of the design process can be a validation process in itself - but only if the elements of the design process and the verification of design qualities can be documented and their value substantiated through describing aspects of the design process.

A second reason to provide a better account of the design process is to convey practical design knowledge to practicing designers. To them, the way the design qualities are catered for in the design process is crucial, and the various design elements that end up in the produced system can be a source of inspiration. A way to look upon designers' knowledge can be inspired by Schön and his way of describing practitioners' knowledge as a design repertoire rather than

Permission to make digital or hard copies of all or part of this work for personal or classroom use is granted without fee provided that copies are not made or distributed for profit or commercial advantage and that copies bear this notice and the full citation on the first page. To copy otherwise, or republish, to post on servers or to redistribute to lists, requires prior specific permission and/or a fee.

NordiCHI 2008: Using Bridges, 18-22 October, Lund, Sweden Copyright 2008 ACM ISBN 978-1-59593-704-9. \$5.00

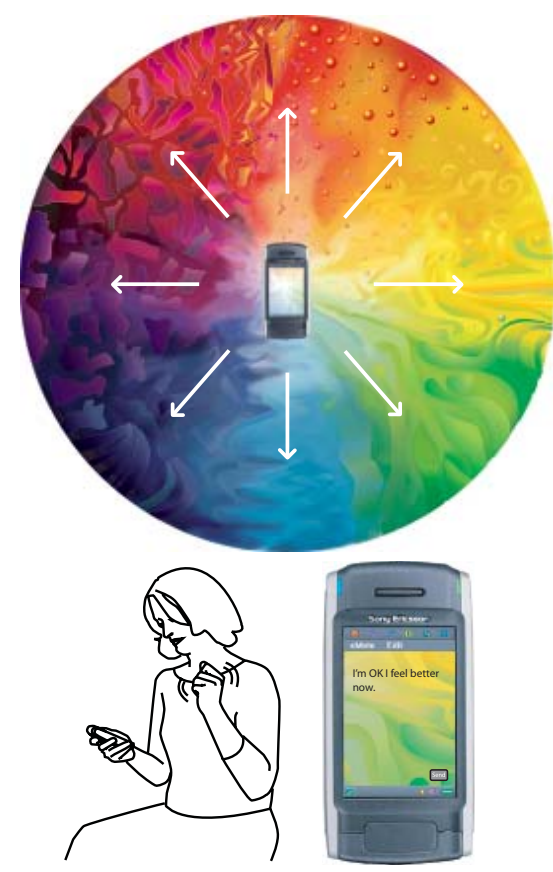

Figure 1. eMoto, the user navigates through gestures on a background with emotional expressions, the expression is then added to the text message.

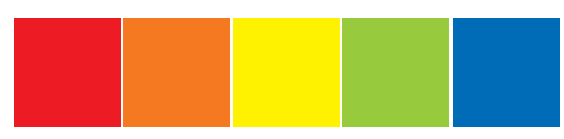

Figure 2. Energy content from red to blue [7].

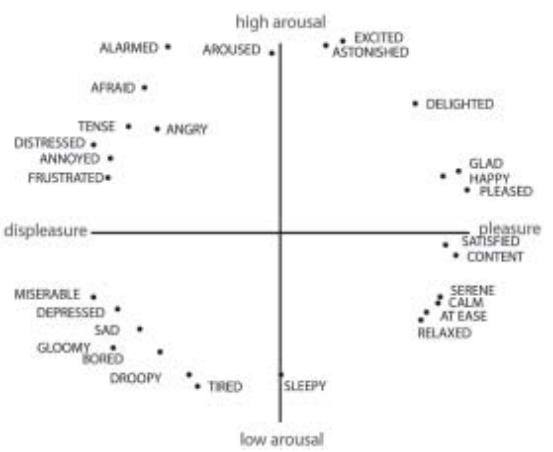

Figure 3. The circumplex model of affect [6]. 
a set of abstracted, scientific rules [8]. While HCI-researchers look for abstracted, generalized guidelines and rules, design-researchers may aim to provide reflected accounts of specific design cases that can feed into a design repertoire.

\section{THREE DESIGN QUALITIES FOR EMOTIONAL EXPRESSIVITY}

The Affective Diary design process builds on a previous design process of a mobile emotional messaging service named eMoto (figure 1), [9]. A reflected account of the eMoto design process can be found in a previous publication [11], but we provide some insights here to show how we made use of those experiences in the next design process.

eMoto is a mobile messaging system that allows users to express their feelings to one another. Emotions are seen as bodily, holistic experiences, co-constructed and co-interpreted processes between those who communicate through the system. To allow users to express themselves and their emotions in richer ways than using text, we based our work on theories of animations, colour and shape. And since we wanted users to express themselves using their whole bodies, we had to find a way to mirror their bodily gestures in the colours, shapes and animations. We asked an actor to express different emotional processes [9]. By combining the insights from the actor study with the psychologist Russell's Circumplex Model of Affect [6] (figure 3), we decided to portray emotions along two axes: arousal and valence. We connected users' gestures with the system to the animated shapes, through basing both on these two dimensions.

The psychological effects of colours have been studied by Ryberg [7]. He describes colours as having different amount of energy; where red in a scale of colours represent the most powerful and strong emotions and blue means moving towards less energy (figure 2). We used other theories for shapes and animations [9].

The experience and analysis of the eMoto design process helped us to start formulating a set of desirable design qualities relevant to designing for emotional expressivity. Along the lines of the design repertoire discussion above, we want to point out that these qualities are not generally applicable to any emotional communication system, but constitute a slightly abstract, reflected account of the specific experiences gained from the eMoto-design case. The extracted qualities were:

Provide cues of emotional expressivity building on familiarity: A non-anthropomorphic representation, using colours, shapes and animations (as in eMoto) is preferable to one that tries to imitate 'natural' human facial, bodily expressions, since it can touch upon our experience of emotions rather than how they are portrayed. But the risk is that those abstract representations become incomprehensible to users and they have to learn what they mean - almost like a new language. It is therefore important that the expressions feel familiar to users, that they can recognise their own experiences in the interaction with the expressions. While being familiar to users, they also need to be open-ended enough to allow users to read their own subtle emotion nuances into them.

Open for personal expressivity: We need to strike a good balance between making the user an active co-constructor of emotion expressions versus making a too strong, interpretative design that does it all for the user. If the emotion expression has to be built from scratch the demand on the user in understanding what they want to convey becomes too high, since we are often not really aware of exactly what we want to express. On the other hand, providing users with too distinct and perhaps even labeled cues (such as smilies) does not leave much leeway for interpretation or personal expressivity. The designer also needs to find the right place on a scale from abstract to depictive cues. Abstract and ambiguous cues allow for personal expressivity and meaning-making by the users, but if they are too abstract they become incomprehensible. As emotions are not singular states but mixed, complex, processes, the expressions must also be designed to allow for blending of the expressions.

Be aware of contradictions between modalities: In many cases, a design will be a combination of several different modalities. In eMoto we used colours, shapes and animations, but we can easily imagine using all sorts of modalities - physical, visual, auditory and so on. When designing the various cues in each of these modalities, it is important that they harmonize and strengthen one-another rather than being contradictory. And when a contradiction is used, the designer should be doing it purposefully with the aim of, for example, creating subtle or dynamic expressions mirroring how emotion processes can be subtle, complex, and combined.

\section{A REFLECTIVE ACCOUNT OF THE DESIGN PROCESS}

Let us now try to put words on those processes that are often 'black-boxed' in descriptions of design work for the Affective Diary design process. Affective Diary aims to represent embodied

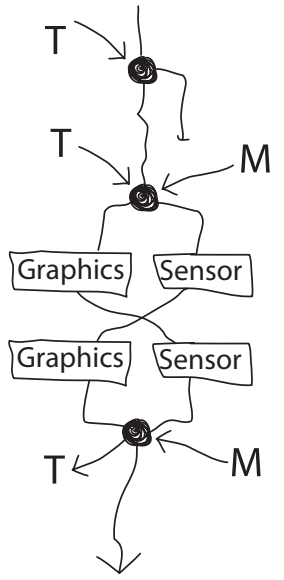

Figure 4. A design process, where the graphics and the technical side are tested in parallel, having impact on one another.

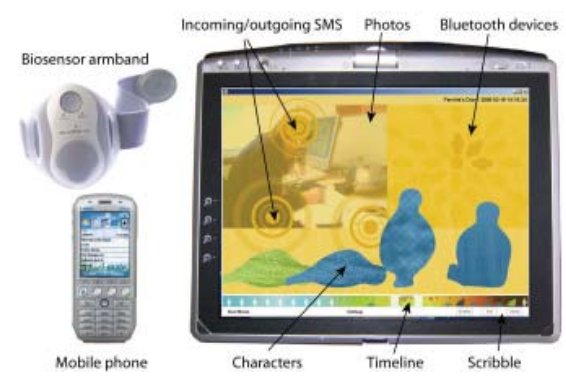

Figure 5. The Affective Diary system design.

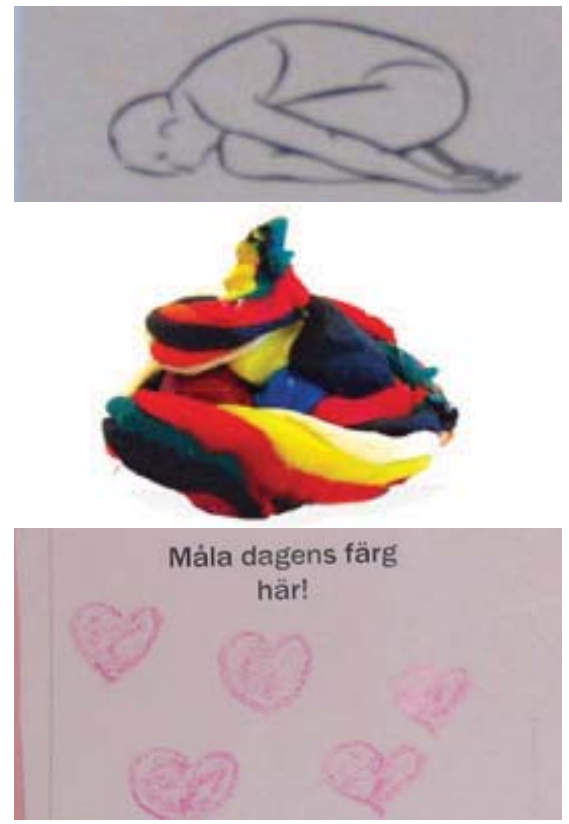

Figure 6. For example, we asked participants move into certain yoga positions and report on their experiences; we encouraged them to write about and make clay sculptures of their bodily experiences of emotions and we asked participants to visually describe their days.

In drawing the colour of the day it became evident how colour and shape are very closely connected where one woman did not only paint in pink but also painted pink in the shape of hearts 
emotional experiences involving both body and mind as one in an emotional interactive system. The aim was to create a tool where bodily and mobile memorabilia could be juxta-positioned with users' own diary scribbles, mirroring users' everyday experiences. This would be the basis for reflections on our everyday lives and emotional experiences. The approach of the design process, as well as of the actual design itself, uses an interactional perspective [1] on how emotion is constructed and experienced. The design qualities extracted from the eMoto design process were therefore considered as a suitable input to the Affective Diary design process.

In a design process, there are many dead ends that provide useful clues to how the final solution was formed sometimes they show why the design is a valid solution. The process is of course not linear, even if we have to portray it as such below. In the Affective Diary project, there were two parallel tracks of design work that fed into one-another (figure 4). Let us start by providing a short system description before we describe the design process - starting with the track that concerned design of the graphical expressions in the diary.

\section{Affective Diary - System Description}

The Affective Diary consists of a mobile phone (with camera), body sensors placed in a bracelet that users wear on their upper arm, and a Tablet PC (figure 5). As a person starts her day she puts on the body sensor armband. During the day, the bracelet collects sensor data on movement (by pedometer data) and arousal (from GSR-readings) of the user. Activities on the mobile phone are logged, such as text messages, photographs and Bluetooth presence. Once the user is back at home she can transfer the logged data into her Affective Diary system on the Tablet PC. The collected sensor data is presented as somewhat ambiguously shaped and coloured 'characters' placed along a timeline. Above the characters, the materials from the mobile phone are placed (figure 5). To help them reflect on the day, the user can interpret and alter the representation: changing the posture or colour of the characters, scribbling diary-notes onto the diary.

\section{Graphical design}

Cultural Probe: To get some first inspiration and ideas on how people's everyday bodily experiences of emotions are expressed in both words, but also visual ways, we performed a cultural probe study [2] with 12 informants (figure 6).

From the collected material we got small glimpses and insights from each participant's life that triggered our imagination. It helped us to sketch, using pen and paper, graphical representations of bodily memories portrayed in the probe materials. The probe-materials showed us that people do not only reflect on past experiences, but also on expected experiences and hopes. Our informants wished to express their inner thoughts and emotions, to relive specific moments in their life - both positive and negative experiences.

Inspirational Material and Sketching: We combined the inspiration we got from the probes materials with the design qualities from eMoto. To provide familiar cues in the different modalities, we picked up on the colour theory, form theory, and human postures. An image board was put together (figure 7), complementing the pictures and colours the probes-informants had sent us. This lead to a broadly aimed sketching phase (figure 8), that was then narrowed down into three different concepts.

Three Concepts: We named the three concepts the Person-Situation Concept, the Collage Concept and the Posture Concept.

The Person-Situation Concept focuses on the finding that emotional processes often revolve around a specific person or situation. In the imagined interaction, the user herself does all sorting and arranging of data into her own time periods and placing them surrounding persons and/or situations. In this concept the data is represented at a very abstract level, not so much interpretation of the data is done, and the only cues that provide some familiarity are portrayed in colour. The representation is very open for interpretation. (Figure 9).

In the Collage Concept the focus was on allowing users to change, massage and arrange the data in a direct-manipulation manner. The sensor-data is translated into coloured, differently sized and shaped collage-scraps. These are combined into an art-like representation showing a day, an hour or a week that the user can work with much like when you create a collage, by ripping, moving and gluing scraps and bits into the picture. (Figure 10).

In the third concept, the Posture Concept, the data is represented more as a story over time. The system translates the bio data into postures and colours as cues of familiarity in a more depictive way than the previous two. The representation is still fairly open, as the anthropomorphic representation is not entirely depictive. The idea is that users should be able to alter the postures of the character and thereby change the story of their everyday life. (Figure 11).

Evaluation and Discussion of Concepts: These concepts were evaluated in terms of how well

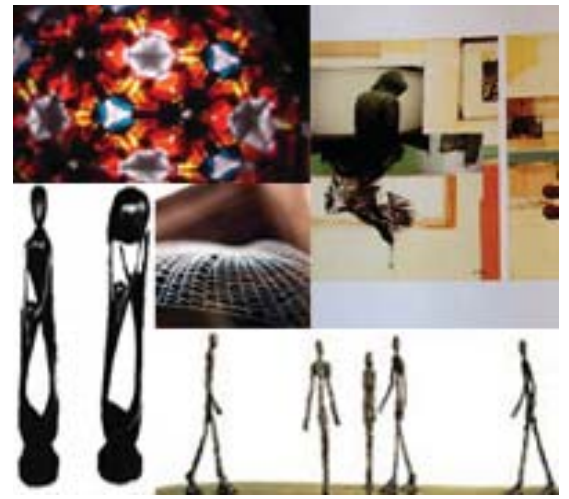

Figure 7. The image board.

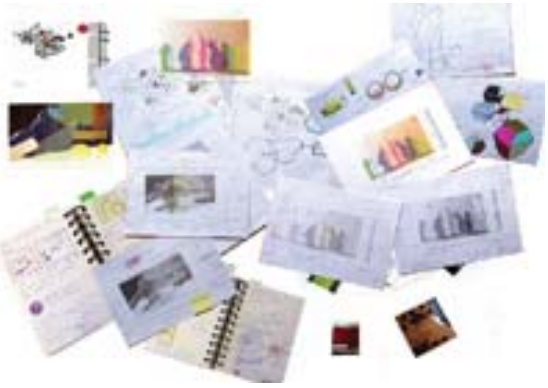

Figure 8 . The broad sketching.

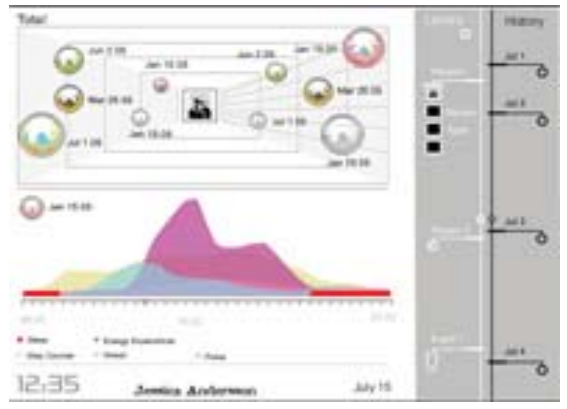

Figure 9. The person-situation concept.

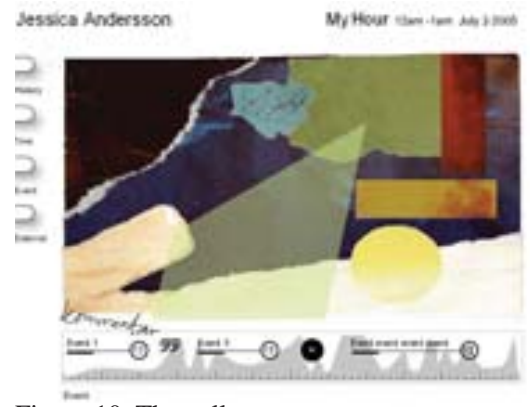

Figure 10. The collage concept.

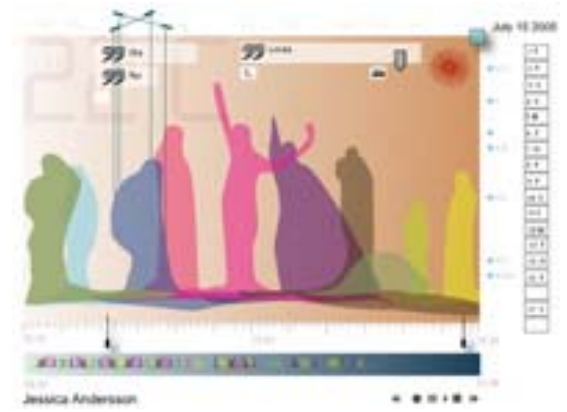

Figure 11. The posture concept. 
they captured the findings in the cultural probes and in how well the desirable design qualities came through in the designs. (The material for each concept consisted of sketches made in Illustrator and visualisations of animated parts in Flash illustrating their dynamic properties and functionality). From the cultural probe we had learnt that some kind of time representation allowing for comparisons was important.

The Person-Situation Concept allowed comparing and sorting materials, a process which in itself entails working with, reflecting on and perhaps even reliving the experiences. But in terms of providing for recognition, familiarity, of the representation, the use of colour is quite limiting. The balance in terms of openness to personal expressivity weighed too heavy on the abstract side, leaving the user with too few cues to spur a relevant interpretation process. The main advantage of this concept is that it makes it easy to compare different events that concern the same person or situation with one another in a direct, visual manner.

The Collage Concept gave more direct hands-on means to work with and change the collected materials. It represented the data as a summary for a time period. In terms of providing for familiarity, it was quite abstract. It would require that users learnt how to interpret the shapes, their sizes and the meaning of their placements. The representation is maybe too open when it comes to personal expressivity, since it takes some effort to get to the "right" personal expression, even if it is possible. On the other hand, the form language in this collage-like concept was something that we found appealing.

The Posture Concept captured the fact that things happen over time. The cues of familiarity are very strong, building on body posture and colour reminding users of their own body postures and excitement/calmness. By extracting the characteristic, expressive cues that are familiar to us within body posture, this representation provide cues but it still leaves leeway for users to start interpreting. The openness for personal expressivity seemed to be fairly balanced in the representation; it was depictive, but still abstract enough to not convey only one specific personality.

Concept Chosen: Based on its ability to capture and portray the desirable design qualities, the Posture concept was chosen. But it required a means for users to alter and manipulate the characters. Otherwise the system would be in charge of deciding how users' sensor data should be interpreted. Physical movement and arousal are bodily processes that we are aware of and can relate to. In the Posture concept, the more you have been moving the more erect the character posture is. Arousal is represented by colour building on the energy level of different colours discussed above [7]. To add some of the social context that surrounds us and to trigger our memory to be able to interpret the postures, the mobile data was placed along the same timeline, (figure $5)$. The content of the diary is shown over a 24 hour time period, to help users navigate through the day without exactly looking at the time, the background where the bio data and the mobile data is shown changes colour. These colours were inspired from the light and colours that you can see at different times of the day (in Sweden), (figure 12).

Small User Encounter: So far we had only discussed the concept and representations within our project team and decisions were based on learning from previous projects and the probes materials. At this stage it was time to bring in potential users from outside the project. This was done as focus group discussion with four persons. As the system was not yet working, we instead provided them with a story that they had to imagine to be their own past. Since the data portrayed in Affective Diary matching this story was not their own, real data, we could only get some first insights into the functionality and the representation of the idea as such. In short, the users all immediately started interpreting the postures and colours of the characters as having something to do with how they had been feeling and their physical activities. For example, they assumed that red meant having had a high pulse, and a character lying down meant having been tired. They felt that the surface afforded scribbling on top of it to add their own diary notes. When it came to modifying the characters and their colours to better portray what they had experienced, they did not want to change the character in a manner where the initial characters are dismissed entirely. Instead, they wanted to see some kind of shadow left from the initial representation so that they clearly could see where they had made modifications to them. These insights lead to a small redesign of the representation before implementing the system for real.

\section{Sensor Input}

Stage Lived Experience and Mapping of Sensor Data In parallel to developing the graphics we needed to map this representation of users' bodily and emotional everyday experiences to any bio-sensor data we could reasonably obtain from (comfortably) wearable sensors.

We decided to once again work with Russell's circumplex model of affect [6], but to avoid the valence-dimension in the representation as such, as valence of emotion is very hard to read from sensor data. Instead, our idea was to let users add meaning and valence themselves. This is

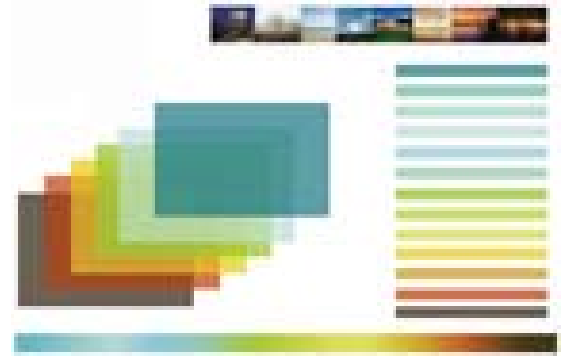

Figure 12. Examples of background colours and inspiration to those.

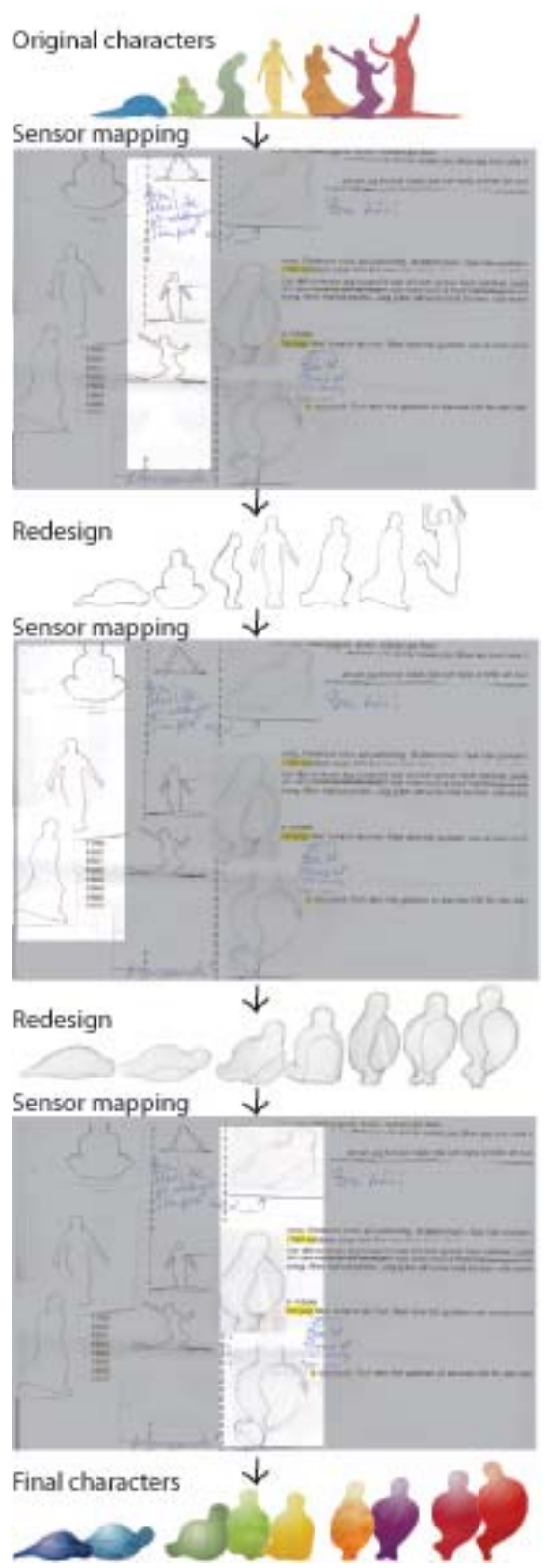

Figure 13. The redesign process of the characters. One example of a character containing valence in the original set, was the character sitting down looked as though it was eagerly listening to someone. This did not map very well to the experience one of the participants had had, participating in a very boring meeting, not listening at all. 
why we decided to only portray the dimensions arousal and movement in the interface. To test this hypothesis, the project team and some outside participants whore a whole range of wearable sensors for 24 hours and maintained a diary of their activities. The sensor data was then mapped to the characters' posture and colour by hand. The use situation was 'faked' (or staged), but still connect to real data, allowing for a realistic, lived experience of the interaction [3].

To see if the seven characters could fulfill the role of reminding us of our bodily experiences, we mapped characters to certain combinations of sensor data. When confronted with the representations, we felt that these characters expressed too much emotional valence, not matching our memories of what had passed. The characters had to be neutral in their appearance. In addition, some of the characters looked female and some male, preventing identification. Finally, there were too few variations in the representations. These insights lead to a redesign of the characters to make them more valence-neutral, less humanlike and two more characters were added to enable a richer set of representations. These new altered characters were mapped out against our sensor data and analyzed once again. The new characters did not portray any valence, but they were too human-like. Some of them were ghost-like, indicating some gliding movements. Each character also had its own personality - they could not blend into one-another to represent one individual throughout. This led to yet another redesign of the characters. The result became a more abstract character with a clearer form language. These were mapped out one last time against sensor data and could better capture all the shifting situations. (Figure 13).

Sensor mappings were very simple: movement was mapped to a pedometer sensor (measures the number and frequency of steps a person takes) and arousal was mapped to the GSR sensor (measures the skins ability to lead electricity, which is an indication of emotional arousal [5]). It should be noted that GSR is also affected by how much you are sweating from physical activities. But since our intention was not to inform users about their emotional states, but to allow them to interpret the bio-data based on their own experiences, this was not necessarily a problem to be solved by processing the sensor data in the system. Instead, we can rely on users to sort this out. If you have been to the gym you probably remember this and can make sense of your characters anyway.

The highs and lows in GSR-readings were calculated relative to each 24 hour period and mapped out to a maximum of five most significant states within each hour, using nine different movement states (represented by the nine different characters) and nine arousal states (using nine different colours). This is an approximation, but it was capturing enough to allow us to experiment with our overall design idea.

\section{Putting the Design to Test}

Short Term User Encounter - Verification of Design: We tested the implemented system with three users for a period of one to three days. They could easily relate their everyday life to the diary materials and provided us with elaborate stories on how they had interpreted situations based on the characters and mobile data. What became evident was that, to be really useful, Affective Diary should be used for a longer time period to make the novelty effects wear off and to allow users to start observing patterns in their data.

Long Term User Encounter: We let four participants use Affective Diary for 2-4 weeks each (described in more detail elsewhere [10]). They used the system in two turns. After each turn we conducted a video-taped interview, where the participants showed us their diary, including their own diary scribbling, discussing their interpretation of it. Concerning the three design qualities outlined above, we got the following insights:

Provide cues of emotional expressivity building on familiarity: The aim with providing these cues is that users should feel familiar with them and be able to use them for interpreting the bio data. In Affective Diary, all four of our participants understood, at some level, that their movements and arousal level were portrayed as postures and colours of the characters. One participant discussed how the erect postures of the characters showed that she had been out jogging (figure 14). Another participant commented on first lying down in her bed and then getting up (figure 17). All four participants connected colour to arousal, in accordance with the theories of Ryberg. One of our subjects, for example, interpreted the colours to represent a range of emotional reactions related to her meditation (figure 15). Another participant associated the red colour of some of her characters to the arousal she felt while playing the violin.

Open for personal expressivity: The next question was whether users could become active co-constructor of emotion expressions and interpretation of what the system provides without reading anything randomly into the representation? From the study, we could extract several examples where the participants could, from almost the same representation, infer different experiences and emotional interpretations. One user had two different situations with similar

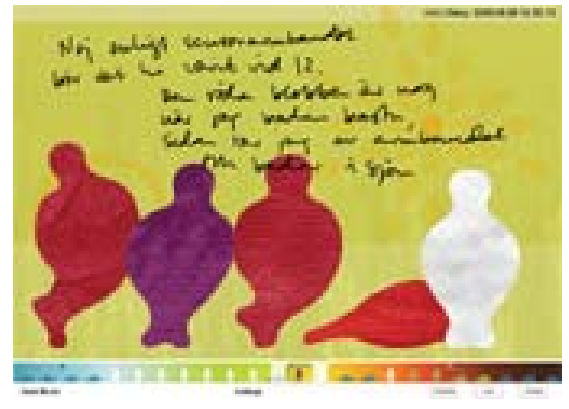

Figure 14. "I am out jogging, and then I take off the bracelet while taking a sauna bath and swimming in the lake."

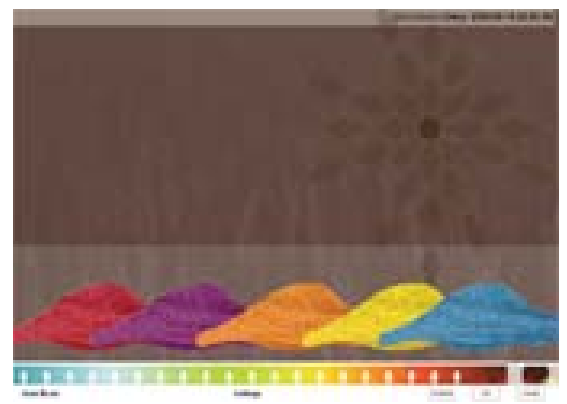

Figure 15. "Usually I meditate before work and late in the evening. That is probably it, because then I go through several states...”

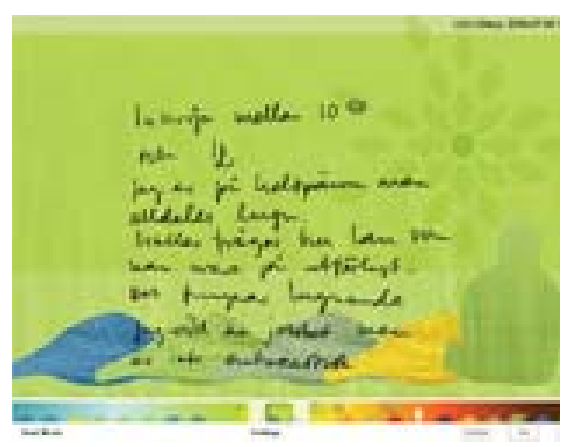

Figure 16. "I'm at a work interview, I start asking him things so he just keeps on talking that totally calms me down, when he reacts like that."

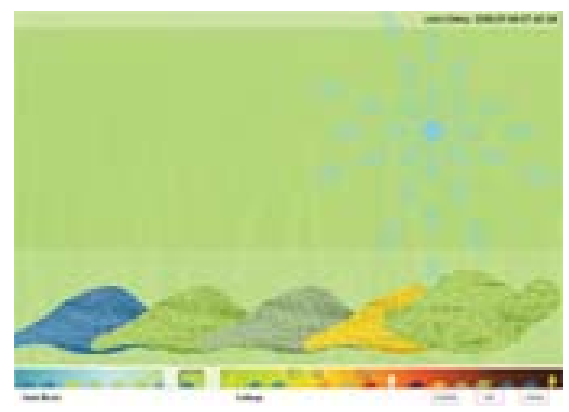

Figure 17. "Here it's night time. I am a sleep. Then something happens here. Yes, here I wake up and then I get out of bed." 
representations that she interpreted totally differently (figure 16 and 17). Between participants in the study, there were also different interpretations of the characters. Based on the two fairly similar screen dumps, figure 18 and figure 19, the two users provided us two quite different stories.

To allow for constructing personal, subjective meaning from what the system offers, the design of the cues needs to find a suitable level on the scale from abstractness to depictiveness. While each character in Affective Diary allows for an open-ended interpretation based on its shape and colour, a problem with the characters is that they, in a sense, portray users' experiences as distinct states. The Affective Diary system will map them out as several characters along the time-line. The character-representation was, in this sense, too depictive, too 'closed' - mainly due to the posture of the character. This sometimes clashed with users' expectations. (Figure 20).

Users could alter the characters by changing their posture or colour, but none of our participants did so. After the study it became evident to us that changing the character only strengthens the feeling of dismissing the representation instead of processing and interpreting it. If the level of ambiguity had been better at capturing the blending properties between states and emotion processes, the characters would instead have worked as a starting point for interpreting and providing meaning to the representations.

Two of the four participants overall had more difficulties in relating to the Affective Diary representations. Many of their difficulties originated from the 'closed' form of the characters making them look as if they mirror the bio data, state by state. Instead they should, probably, have portrayed a more open-ended, ambiguous shape, allowing for the right kind of interpretation (figure 21).

Be aware of contradictions between modalities: In the Affective Diary we used single, separated cues for expressing movement and arousal and these could and should be combined in all ways, so there were not any contradictions to be aware of. But the expression might have been more powerful and richer if we had combined more cues expressing for example movement, then one had had to be more careful in the way these were portrayed in the design.

\section{DISCUSSION}

We have provided some reflections on the design process of Affective Diary. By articulating and describing the transformation of the three design qualities into specific design element we have put words on what is often black boxed in HCI-literature. While the insights from the design process are specific to Affective Diary it provides yet one more example, besides eMoto, that can used as inspiration for other designers, showing how they can work with similar qualities in their own work.

Being sensitive to how to provide cues of emotional expressivity building on familiarity proved to be an important key to success in Affective Diary. To open for personal expressivity proved to be a bit more complicated. This design quality is harder to accomplish since the right balance for the specific design case has to found. And the failures in this respect in Affective Diary show just how complex and delicate this balance is. It has to be fine-tuned and tested to reach the right level of ambiguity, be abstract enough and thereby capture the important blending properties of emotional expressions. To be aware of contradictions between modalities was never a problem in this design process since the expression modalities were separated and could also be contradictory.

In summary, Affective Diary needs to be taken through another design cycle, refining the design based on the last user encounter. A new representation needs to better integrate and display the process of experiencing emotions, blending experiences into one-another.

\section{REFERENCES}

[1] Boehner, K., DePaula, R., Dourish, P., and Sengers P., (2005) Affect: From Information to Interaction. Critical computing Conference 2005, Århus, Denmark.

[2] Gaver, B., Dunne, T., and Pacenti, E. (1999) Design: Cultural Probes, Interactions, 6(1), pp. 21-29, ACM Press.

[3] Iacucci, G., Iacucci, C. and Kuutti, K. (2002) Imagining and experiencing in design, the role of performances, Proceedings of the second Nordic conference on Human- computer interaction, Aarhus, Denmark, pp. 167 - 176

[4] Kaye, J., and Sengers P., (2007) The Evolution of Evaluation. alt.chi, CHI 2007, San Jose CA.

[5] Mandryk, R.L., and Atkins, M.S., (2007). A Fuzzy Physiological Approach for Continuously Modeling Emotion During Interaction with Play Environments. International Journal of Human-Computer Studies, 65, pg. 329-347.

[6] Russell, J. A. (1980) A Circumplex Model of Affect, Journal of Personality and Social Psychology, 39:6, pp. 1161-1178, American Psychological Association.

[7] Ryberg, K. (1991) Levande färger, ICA Bokförlag, Västerås, Sweden.

[8] Schön, D. A. (1983) The Reflective Practitioner: How professionals think in action. London: Temple Smith.

[9] Ståhl, A. (2006) Designing for Emotional Expressivity, Licenciate Thesis, Institute of Design, Umeå University, Umeå, Sweden. [10] Ståhl, A., Höök, K., Svensson, M., Taylor, A., and Combetto, M., (2008) Experiencing the Affective Diary. In Press, Journal of Personal and Ubiquitous Computing.

[11] Ståhl, A., Sundström, P., and Höök, K., (2005) A Foundation for Emotional Expressivity. DUX 2005. San Fransisco CA.

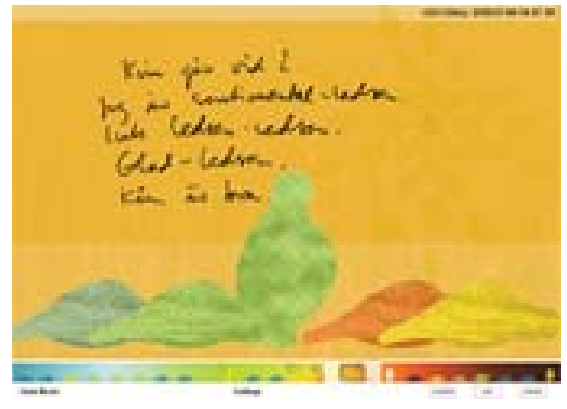

Figure 18. "And then I get like this, I'm like both happy and sad in a way, something like that. I like him and then it is sad because we don't see each other that often."

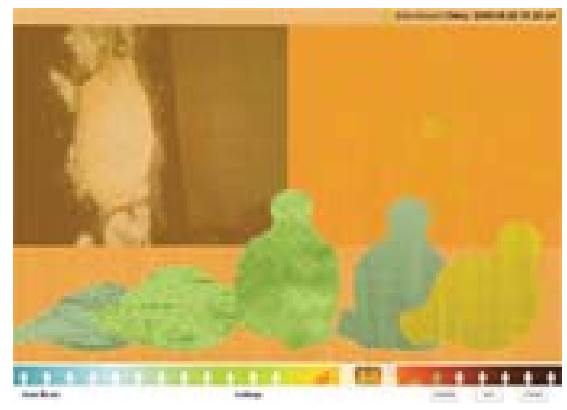

Figure 19. "Here I was at home baking for midsummer's eve, so I was very green. It's like: "I love to bake, I love to cook and..." so it was really like green, yellow. Very positive."

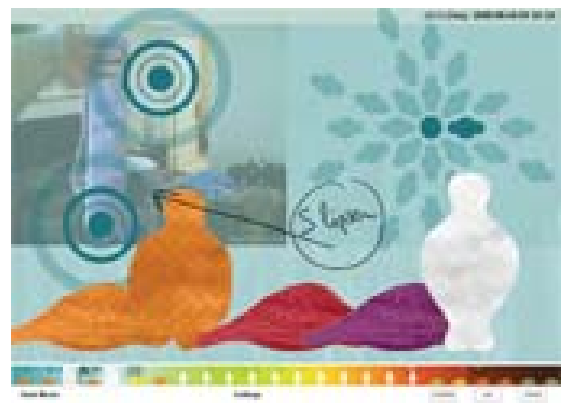

Figure 20. "It is kind of, what does this mean? After a while when you think about it, it doesn't say anything. I have landed and I am a bit tired, like jet lag and then you go to bed, or?"

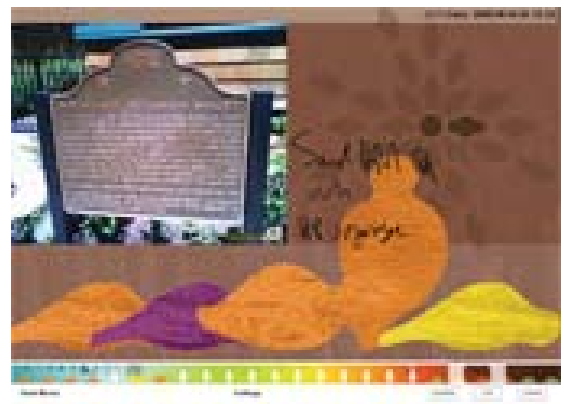

Figure 21. "This character, what am I doing here; I am at a study visit. What happens now? It does not have any connection to what I did, not at all." 